\title{
Value, polish, strength in just
} one visit

\section{BRILLIANT COMPONEER is}

COLTENE's answer for dentists who want a minimally invasive restoration that can be delivered in a single visit.

When developing this system, COLTENE used the same sub-micron filler technology as its popular BRILLIANT EverGlow. Based on pre-fabricated veneer shells, you can make a smile brilliant in one session, no lab required. The shells exhibit strength, polishability and long-lasting gloss; speed does not compromise a great result.

Another benefit of BRILLIANT COMPONEER is value: for you and your patients.

Try BRILLIANT COMPONEER then discover the rest of COLTENE's restorative tools and materials for exceptional, upgraded dentistry.

To find out more about COLTENE, visitwww.coltene.com, email info.uk@ coltene.com or call 01444235486.

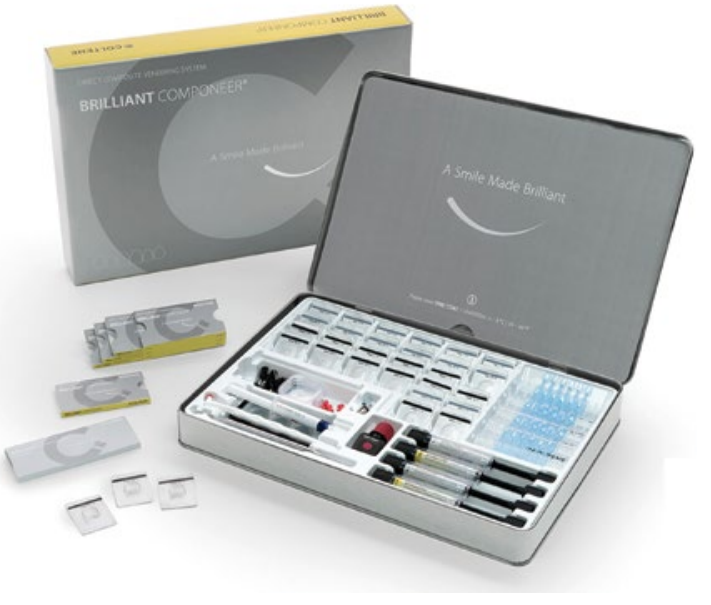

\section{First choice for first class disinfection}

Designed to help practices achieve first class disinfection safely, effectively and simply, the ThermoKlenz thermo washer disinfector dryer should be the first choice for any practice aiming for quality results.

Distributed by leading decontamination experts $\mathrm{W} \& \mathrm{H}$, the ThermoKlenz offers

\section{Introducing contactless reception}

Dentally has announced new contactless reception features including online medical history, self-check-in and payment links, that have been integrated into the software to support dental practices with social distancing and COVID-19 guidelines.

As part of a contactless reception process patients will need to complete a medical history. Online medical histories allow patients to complete their medical history themselves via a unique link.

Once the patient clicks on the link it will take them to their medical history; once the patient completes the questions, they click to sign it and save it. As soon as the medical history has been completed it will appear in the patient's record in Dentally - and will show as being completed by the patient. The dental practitioner can then review the medical history as they would do normally and click to say they have done so.

The self-check-in features allow the practice team to send an SMS to patients arriving just prior to an appointment time at the practice. The patient can click on this link and check themselves in as they arrive on site, this will change their status within the Dentally software to 'Arrived'.

It is simple to set up for the dental practice; you just need to use a new data tag in a default set SMS. When the patient clicks on the link, it will take them to a page that allows them to check in 30 minutes prior to their appointment.

If the patient clicks on the link before the 30 minutes, then the page will display a message to advise them that check in is not yet open. This prevents anyone from checking in too early.

Once the dental practitioner has said goodbye to the patient and they have left the surgery - rather than a member of the staff having to have physical contact with the patient to take payment, it can now be done securely through a SMS sent straight to the patient.

The practice team can now send the payment link as soon as the patient has left the surgery or at certain times during the day as a bulk exercise. As you would expect from Dentally, this new functionality is easy to set up. To use this functionality, you will need to have a Stripe account for the payment.

Once you have this, you can create a payment screen - which can be customised to include your practice logo and details. The payment page is fully responsive and will work for whatever phone, iPad or device the patient is using.

You can then create a SMS message with the information you wish to include and a data tag for the secure link to your payment page.

Once it is sent to the patient, they see a secure link that allows the patient to pay the bill by clicking on the link to the payment page, using a credit/debit card, Apple Pay, etc. All of the relevant information, such as the patient's name and the payment due is shown on the payment page. Once completed, the payment will update the patient record within Dentally.

By using these new contactless reception features, it will help dental practices limit the number of staff members the patient has to come into contact with during their visit for dental care but helps retain a seamless patient experience.

If you would like more information on how Dentally can make your life easier as you reopen your dental practice with their special toolkit of features, then email hello@dentally.co to talk to the team. both effective cleaning through the automatic regulation of water temperature and detergent quantity, and drying through forced hot air that reduces residual moisture internally and externally. This ensures that instruments are $100 \%$ ready for sterilisation.
The ThermoKlenz is available with a KlenzSecure data logger, so that practices are able to keep electronic records of cleaning cycles - much more efficient than a paper trail. To find out more visit www.wh.com/en_uk, call 01727874990 oremail office.uk@wh.com. 